\title{
Impact of paint matrix composition and thickness of paint layer on the activity of photocatalytic paints
}

\author{
Piotr Homa*, Beata Tryba, Andżelika Gęsikiewicz-Puchalska \\ West Pomeranian University of Technology Szczecin, Faculty of Chemical Technology and Engineering, Institute \\ of Chemical and Environment Engineering, Department of Water Technology and Environment Engineering, Pułaskie- \\ go 10, 70-322 Szczecin, Poland \\ "Corresponding author: e-mail: piotr.homa@zut.edu.pl
}

\begin{abstract}
Silicate, acrylic and latex photocatalytic paints were analyzed in regards to impact of paint matrix composition and paint layer's thickness on performance in two photocatalytic tests. These included performances in photocatalytic decomposition of benzo[a]pyrene (BaP) and assessment of photocatalytic activity through use of smart ink test. Silicate photocatalytic paints displayed lower photocatalytic activity in comparison to acrylic and latex photocatalytic paints in both tests, despite the similar content of nanocrystalline $\mathrm{TiO}_{2}$. Measurements of depth of UV light penetration through the paints layer were performed and it appeared, that more porous structure of coating resulted in deeper penetration of UV light. In the case of acrylic paint, the thickness of the photocatalytic layer was around $9 \mu \mathrm{m}$, but for silicate paint DR this thickness was higher, around $21 \mu \mathrm{m}$.
\end{abstract}

Keywords: photocatalytic paint, smart ink test, UV absorption, benzo[a]pyrene decomposition, paint coating thickness.

\section{INTRODUCTION}

Application of $\mathrm{TiO}_{2}$ film coatings or photocatalytic paints containing $\mathrm{TiO}_{2}$ for self-cleaning surfaces is recently developing a new method of improving the quality of indoor and outdoor air ${ }^{1-10}$. Multiple research studies were performed in order to investigate the influence of paint formulation on the photocatalytic activity of $\mathrm{TiO}_{2}$ particles mixed within the paint matrix. It has been proven that $\mathrm{TiO}_{2}$ could be deactivated after coverage of its surface by $\mathrm{SiO}_{2}$ particles ${ }^{11}$. It was reported that pigmentary $\mathrm{TiO}_{2}$ in paints competitively absorbs the UV light and therefore can decrease the photocatalytic activity of paints ${ }^{12,13}$. It was evidenced that the presence of up to $5 \%$ of pigmentary rutile resulted in acceptable photocatalytic activity but further increase of rutile content negatively affected this activity ${ }^{13}$. However, in the case of photocatalytic paints based on polymer dispersion, where anatase particles are more exposed to UV, destruction of the soft organic matter (i.e. binders) during the photocatalytic process can occur ${ }^{13}$. As a consequence of this - after some period of UV irradiation - the activity of such photocatalytic paints might be increased ${ }^{13,14}$. To summarise, in most cases photocatalytic paints based on the polymer dispersion have higher photocatalytic activity than those based on silicates. Nevertheless, some of the composites of $\mathrm{TiO}_{2}$ with $\mathrm{SiO}_{2}$ in which $\mathrm{TiO}_{2}$ particles are only partly covered by $\mathrm{SiO}_{2}$ can exhibit comparable activity with anatase particles ${ }^{11}$. It was reported that photocatalytic paints based on polymer dispersion could be efficiently applied for both, interior and exterior surface coatings, reducing concentration of some pollutants such as $\mathrm{NO}^{10,12}$, volatile organic compounds $(\mathrm{VOC})^{15}$, polycyclic aromatic compounds (PAC) $)^{5,16}$ and can also lead to deactivation of bacteria ${ }^{17}$. Mineral photocatalytic paints usually exhibit lower photocatalytic activity than the acrylic ones, but they have better stability during exposure to solar radiation ${ }^{18}$.

For practical application of the photocatalytic paints it is important to determine the optimal thickness of the paint layer which is active under irradiation of light, because photocatalytic paint should be used only as an outer layer for coating. Therefore, the depth of light penetration through the paint layer should be measured. Such measurements can determine the layer thickness in which photocatalytic process occurs. Beyond this layer only adsorption of pollutants takes place.

There are some reports in literature which show that the thickness of the photocatalytic paint can affect the yield of the photocatalytic process ${ }^{19-22}$. By increasing the thickness of the photocatalytic film the number of available active sites can also increase, although for film thickness higher than the optimal overlapping of the active $\mathrm{TiO}_{2}$ nanoparticles can occur and cause reduction of active sites as well as recombination of free carriers ${ }^{23}$. Influence of the film thickness on the rate of electrons transfer to semiconductor's surface was also considered in regards to photocatalytic decomposition of textile dyes $^{24}$. It was reported that in thicker films electrons can travel further before returning to the surface of the semiconductor, making recombination process slower and implying higher photocatalytic efficiency, owing to a greater density of $h^{+}$at the surface. In very thin layer this effect is too fast due to shorter electron path resulting in a lower efficiency. However, in very thick films other effects related to the opacity of the film may take place, reducing the activity ${ }^{24}$. Contrary, different authors noted that for the layer above $545 \mathrm{~nm}$ generation of carriers remained constant but migration length of carriers to the surface of the catalyst increased, along with recombination rate, resulting in a decrease in the photocatalytic activity towards rhodamine $\mathrm{B}$ decomposition in water ${ }^{25}$. However, Chen and Dionysiou ${ }^{26}$ reported increase of the photocatalytic activity of films towards decomposition of 4-chlorobenzoic acid by increasing the film thickness up to $10 \mu \mathrm{m}$. The activity of such thick film was explained by its high BET surface area and porosity. Generally speaking, more porous structure of $\mathrm{TiO}_{2}$ film generates more active species and as a consequence higher photocatalytic activity of this film is obtained ${ }^{26,27}$. 
In our previous paper it was already reported that silicate paints exhibited low photocatalytic activity. However, in the previous measurements the thickness of painting layer was not considered. Therefore in these studies the depth of UV absorption through the paint layer was measured in regard to its porosity in order to judge the photocatalytic effect occurring up to the limit of UV light penetration. Two photocatalytic tests were applied, BaP decomposition and smart ink test.

\section{MATERIAL AND METHODS}

\section{Photocatalytic paints}

Presented studies utilized four commercial white colour photocatalytic paints (PIGMENT, Poland). These included two water-based silicate paints - FA and DR, as well as water based latex - LX, and acrylic - IN paints. FA and DR paints were designed for painting interior and exterior construction elements (also roads in case of DR paint) and contained antibacterial and antifungal additives. LX latex paint was designed for indoor applications - painting walls and ceilings in rooms requiring frequent wet cleaning. This paint also contained addition of nanoparticles of silver, responsible for improved antibacterial and antifungal properties. IN paint was designed for painting interior walls and ceilings. All of these paints contained pigmentary $\mathrm{TiO}_{2}$ in form of rutile as well as nanocrystallic anatase $\mathrm{TiO}_{2}$. Anatase to rutile ratio in all the paints was equal to $1: 2$. While all of paints contained calcium in form of a mineral filler $\left(\mathrm{CaCO}_{3}\right)$ its content was much higher in case of water-based silicate paints (FA, DR). In addition these paints also contained potassium as a result of addition of potassium water glass. Both $\mathrm{CaCO}_{3}$ and potassium were proven to be highly influential on the photocatalytic performance of water-based silicate paints ${ }^{\mathbf{1 6}}$. All of the paints contained some amounts of aluminium and silica compounds, while LX paint contained large agglomerates of aluminium silicates. All of the paints also contained trace amounts of sulphur, possibly due to use of titania pulp (obtained from hydrolysis of $\mathrm{TiOSO}_{4}$ ) as a source of anatase phase. They have also contained magnesium in form of a mineral filler $-\mathrm{MgCO}_{3}$. Detailed chemical analysis of said photocatalytic paints can be found in our earlier work ${ }^{16}$. For reference elemental content of the tested photocatalytic paints analysed by SEM-EDX was listed in Table 1.

Table 1. Elemental content of photocatalytic paints analyzed by SEM-EDX

\begin{tabular}{|l|c|c|c|c|}
\hline \multirow{2}{*}{ Element } & FA & DR & IN & LX \\
\cline { 2 - 5 } & \multicolumn{4}{|c|}{ wt\% } \\
\hline $\mathrm{C}$ & 6.6 & 8 & 14.7 & 13.5 \\
\hline $\mathrm{O}$ & 52.5 & 54.5 & 59.6 & 58 \\
\hline $\mathrm{Na}$ & 1.1 & 1.1 & 1.5 & 0.6 \\
\hline $\mathrm{Mg}$ & 3.1 & 3.4 & 4.7 & 3.2 \\
\hline $\mathrm{Al}$ & 0.4 & 0.45 & 1.1 & 4.1 \\
\hline $\mathrm{Si}$ & 3.8 & 3.9 & 0.4 & 3.3 \\
\hline $\mathrm{S}$ & 0.4 & 0.35 & 0.2 & 0.1 \\
\hline $\mathrm{K}$ & 2.9 & 2.3 & - & - \\
\hline $\mathrm{Ca}$ & 13.9 & 12.4 & 2.1 & 2 \\
\hline $\mathrm{Ti}$ & 15.3 & 13.6 & 15.7 & 15.2 \\
\hline Total & 100 & 100 & 100 & 100 \\
\hline
\end{tabular}

\section{Chemicals}

Chemicals used for preparation of smart ink - hydroxyl ethyl cellulose, glycerol, resazurin ( $75 \%$ dye content) and TWEEN® 20 surfactant were supplied by Sigma-Aldrich. Preparation of the ink was performed according to procedure described by Mills et al. ${ }^{27}$. A mixture of 20 $\mathrm{g}$ of $1.5 \mathrm{wt} \%$ hydroxyl ethyl cellulose solution in high purity water (conductivity $\leq 2 \mu \mathrm{S} \mathrm{cm}^{-1}$ ), $2 \mathrm{~g}$ of glycerol, $20 \mathrm{mg}$ of $\mathrm{Rz}$ and resazurin $\mathrm{mg}$ of TWEEN® 20 surfactant was prepared. In order to ease the application with aerograph obtained mixture was further diluted with additional $20 \mathrm{~cm}^{3}$ of high purity water. Obtained ink was then stirred with magnetic stirrer for $8 \mathrm{~h}$ and later stored in a refrigerator. Before its application ink was removed from the refrigerator and stirred for $1 \mathrm{~h}$ on a magnetic stirrer at room temperature.

Benzo[a]pyrene (BaP) of HPLC purity was supplied by Sigma-Aldrich. Acetone of analytical grade was supplied by Chempur.

\section{Assessment of photocatalytic activity with use of smart ink test}

Photocatalytic activity of commercial photocatalytic paints was assessed with use of activity indicating ink according to a mechanism presented by Mills et al. ${ }^{28,29}$. This ink, based on resazurin was reduced via photocatalysis to allow for easy measurement of the activity of photocatalytic surfaces, such as commercial photocatalytic paints or sol-gel $\mathrm{TiO}_{2}$ films. Electron-hole pairs were generated on the surface of the paint following the irradiation of the photocatalyst with energy greater or equal to that of the band gap of the semiconductor. Glycerol present in the ink film acted as an electron donor, preventing recombination of charge carriers and allowing the photogenerated electrons to reduce resazurin dye to resorufin. This reduction was monitored by gradual and irreversible shift in colour of the ink from blue to pink. Stability of smart ink was confirmed in blank test performed by Mills et al. on self-cleaning and plain glass samples ${ }^{\mathbf{3 0}}$.

For the photocatalytic tests, glass plates $(20 \mathrm{~mm} \times 20$ $\mathrm{mm}$ in dimension) with matt surface were covered with 5 layers of photocatalytic paint through use of aerograph and were later dried at room temperature for $24 \mathrm{~h}$. Following the drying process 5 layers of smart ink were applied onto the surface of each painted plate, also with use of aerograph. Total volume of ink used to cover each plate was equal to ca. $0.5 \mathrm{~cm}^{3}$. For each paint a batch of 8 glass plates was prepared. All prepared samples were irradiated with UV light in 6 irradiation cycles lasting 60 seconds, for a total time of 6 minutes, under interior temperature of $30^{\circ} \mathrm{C}$ and $30 \%$ of relative humidity. All samples were irradiated inside a cuboid shaped photoreactor (total volume of reactor's chamber - aprox. 51 $\left.\mathrm{dm}^{3}\right)$. The top plate of the photoreactor was built from quartz glass, while acrylic glass was used for bottom and side walls. UV lamp (Philips) was placed directly above the quartz plate and was used as the light source. Irradiance was measured at $50 \mathrm{~W} / \mathrm{m}^{2}$ within the $\mathrm{UV}$ region (315-400 nm). The temperature inside the photoreactor was controlled by temperature controller connected to a heater and a thermocouple. Air circulation inside the photoreactor was provided by a fan. Temperature and 
humidity measurements inside the photoreactor were performed with use of Testo 635 thermohygrometer equipped with a wireless humidity/temperature probe.

Gradual change in colour of the ink throughout the irradiation cycles was recorded via digital photography, using Canon MF 8040cn flatbed scanner. Average individual red, green and blue (RGB) values, i.e. RGB(red)t, $\mathrm{RGB}$ (green)t and $\mathrm{RGB}$ (blue)t after irradiation time $\mathrm{t}$, were determined with use of ImageJ software from images scanned with 300 dpi resolution. For each plate a central area of $11 \mathrm{~mm}$ x $11 \mathrm{~mm}$ was selected. Normalized red $\left(R_{t}\right)$ value was calculated for each plate following irradiation time according to the equation:

$$
R_{t}=\frac{R G B(\text { red })_{t}}{R G B(\text { red })_{t}+R G B(\text { blue })_{t}+R G B(\text { green })_{t}}
$$

Average values were calculated from each batch. Lower values of Rt corresponded to blue colour of resazurin, while higher values of Rt corresponded to pink colour of resorufin. A gradual increase of Rt value during the irradiation process corresponded to the shift in colour due to gradual reduction of resazurin to resorufin.

In addition, key parameters were determined from obtained data, i.e. maximum and minimum values of $R_{t}$,

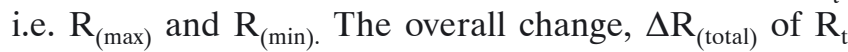
was determined from equation: $\Delta R_{(\text {total })}=R_{(\max )}-R_{(\min )}$. Then the value of $90 \%$ of overall change was calculated as follows: $\mathrm{R}_{\mathrm{t}}(90)=0.9 \Delta \mathrm{R}_{\text {(total) }}+\mathrm{R}_{(\min )}$. Another measured parameter was irradiation time needed for the ink to undergo $90 \%$ of its overall colour change, which was calculated by solving the equation for a polynomial curve fitted to the data at $R_{t}$ value equal to $R_{t}(90)$.

\section{Decomposition of BaP on the surface of the photocata- lytic paints}

Porcelain trays were coated with the photocatalytic paints by using aerograph. Coating surface of the porcelain tray was measured to be about $45.65 \mathrm{~cm}^{2}$. Volume of paint used to cover the tray varied between each experiments. Following the coating process trays were dried at room temperature for $24 \mathrm{~h}$. The photocatalytic decomposition of BaP on the surface of photocatalytic paint was performed with use model solution of $\mathrm{BaP}$ $\left(5 \mathrm{mg} / \mathrm{dm}^{3}\right)$ dissolved in acetone. Each time $1 \mathrm{~cm}^{3}$ of BaP solution was sprayed onto the surface of tray coated with photocatalytic paint. Next, prepared trays with loaded $\mathrm{BaP}$ were left for acetone evaporation at room temperature. Photocatalytic tests of $\mathrm{BaP}$ decomposition were carried out in ATLAS Suntest CPS +/XLS + weathering chamber. The chamber was equipped with a xenon lamp utilizing UV optical filters. Photodecomposition of BaP was performed during 60 minutes of irradiation. For each measurement three repeated experiments were performed. The power of the irradiation was set to $750 \mathrm{~W}$. It was measured that during the irradiation the temperature in the chamber reached up to $50^{\circ} \mathrm{C}$ while relative humidity decreased from 44 to $11 \%$ after 10 minutes of irradiation. The concentration of $\mathrm{BaP}$ was controlled by UV-Vis spectroscopy. Therefore, BaP after exposure to UV was removed from the paint surface by rinsing with acetone and followed by analysis in UV-Vis spectrometer. Calculated $\mathrm{BaP}$ recovery values for each tested paint will be presented later in the results section.

\section{UV-Vis spectroscopy}

The concentration of $\mathrm{BaP}$ was determined through UV-VIS spectra measurements in UV-VIS spectrophotometer (V-650, Jasco). The selected maximum of absorption was at $\lambda=384 \mathrm{~nm}$. It was already checked that at this wavelength there was no absorption of any compounds rinsed from the matrix of the photocatalytic paint and no additional interference from the acetone. The calibration curve of $\mathrm{BaP}$ solution in acetone was preliminary performed.

In addition, some UV-Vis diffuse reflectance measurements were performed utilizing Jasco V-530 spectrometer and $\mathrm{BaSO}_{4}$ as a standard for the baseline.

\section{Field Emission Scanning Electron Microscopy (FE-SEM)}

The thickness of coating was measured by FE-SEM (SU 8020, Hitachi) in cross-sectional cut of selected porcelain trays. Measurements were performed at several points and averaged. Samples were excited with voltage of $5 \mathrm{kV}$.

\section{Absorption of UV light by the photocatalytic paint coatings}

UV-Vis emission spectra of both incident and crossing by the paint layer UV-Vis light were measured by using Ocean Optics USB 4000+. This fibre optic spectrometer allows to measure the full spectrum in the UV-Vis range. The instrument was factory calibrated and delivered together with calibration file, which was used for each measurement. Measurements of light absorption by photocatalytic paint coating were performed with use of same UV light source as the one used in smart ink test (UV light intensity of $50 \mathrm{~W} / \mathrm{m}^{2}$ within the $315-400$ $\mathrm{nm}$ range). For these measurements, quartz plates (10 mm x $20 \mathrm{~mm} \times 1 \mathrm{~mm}$ in dimension) were coated with increasing amount of paint layers (from 1 to 5 ). One of organic - LX and other inorganic - DR paints were used for coating. Spectrum was collected from the end of the optical fibre, which was placed above or beneath the coated and pure quartz plate. Thus, the both, incident light and that after crossing through the quartz plate with coated paint could be measured. The thickness of obtained coatings was measured in cross sectional cut with FE-SEM.

\section{RESULTS AND DISCUSSION}

\section{Photocatalytic activity of paints - smart ink test}

Photocatalytic tests performed with use of smart ink showed that latex (LX) and acrylic (IN) paints exhibited fast conversion of resazurin to resorufin during UV irradiation. Silicate paints (DR and FA) did not display any significant change in $\mathrm{R}_{\mathrm{t}}$ values throughout the irradiation process and appeared inactive. Figure 1 portrays gradual changes of normalized red values in paint samples covered with smart ink. Although it was difficult to replicate paint coatings with exactly the same thickness, however, monitored changes of colour were performed from the surface. As portrayed in Figure 1, recorded values of $R_{t}$ at time zero (before irradiation) were comparable for all the paints, minor variations were within margin of error. Therefore, obtained results are comparable and 


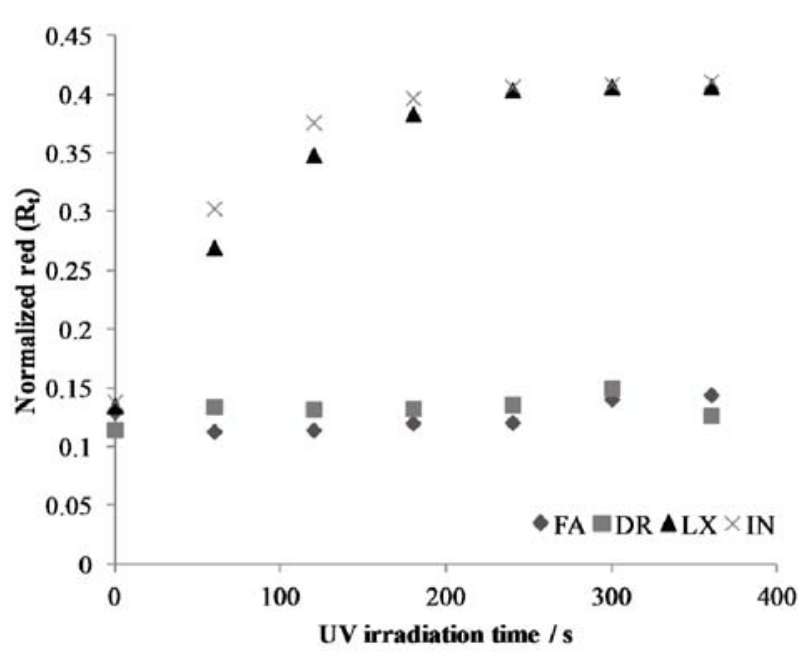

Figure 1. Changes in normalized red (Rt) values during UV irradiation of photocatalytic paint coated samples covered with smart ink

can serve as basic display of photocatalytic performance of individual paints.

Within 250 seconds of UV irradiation maximum values of $R_{t}$ were obtained for both IN and LX paint. $\Delta \mathrm{R}$ was equalled 0.272 and 0.273 for IN and LX paints respectively, whereas $90 \%$ of overall colour change took place within 135 and 167 seconds, respectively. In summary, while overall change of colour was comparable, reduction of resazurin to resorufin proceeded faster in case of IN paint than LX.

UV-VIS/DR measurements were performed along with smart ink test on some samples (specifically for the same single plate in each series). Results of these measurements were presented in Figure 2. It can be observed, that in the case of DR and FA paints there were no signs of colour shifting indicating colour change, which confirmed ink test results. There was only minimal reduction in the intensity of absorption spectra, possibly due to the

FA
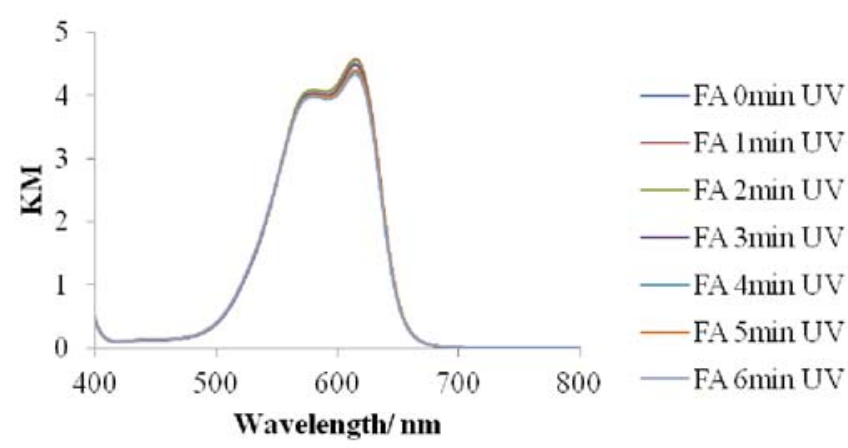

IN

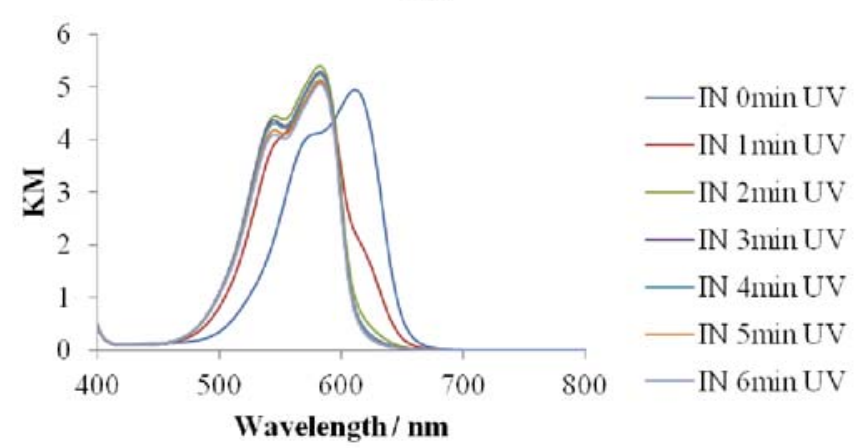

accuracy of measurements or a very minimal bleaching effect. In the case of IN and LX paints a shift in peak absorbance might be observed, from $610 \mathrm{~nm}$ matching resazurin to $580 \mathrm{~nm}$ matching resorufin, which confirms results of the smart ink test.

Obtained results appear to correspond with previous one obtained during BaP decomposition tests, in which silicate based photocatalytic paints displayed activity similar to non-photocatalytic paints ${ }^{\mathbf{1 6}}$. This was proved to be a result of addition of potassium silicate used in paint formulation which blocked access to the active sites containing photocatalytic $\mathrm{TiO}_{2}{ }^{31}$.

\section{Dependence of the photocatalytic paint activity on the coating layer thickness}

In our previous studies photocatalytic decomposition of BaP under UV irradiation on the surface of LX, IN, DR and FA paints was measured for a set volume of paint $\left(2 \mathrm{~cm}^{3}\right)$ used for coating of porcelain tray ${ }^{16}$. Due to the differences in density between paints obtained coatings exhibited different thickness, as illustrated in Figure 3.

By conducting the initial FE-SEM measurements in cross-sectional cut of selected trays used in those studies it was observed that thickness of obtained paint coatings ranged from fairly thin $(16.8 \mu \mathrm{m}$ in case of LX paint) to noticeably thick (approximately $87 \mu \mathrm{m}$ for DR or FA and almost $115 \mu \mathrm{m}$ for IN paints). In Table 2 average

Table 2. Average coating thickness obtained by painting porcelain trays with $2 \mathrm{~cm}^{3}$ of different photocatalytic paints (from FE-SEM)

\begin{tabular}{|l|c|c|c|}
\hline & $\begin{array}{c}\text { Average coating } \\
\text { thickness }[\mu \mathrm{m}]\end{array}$ & $\begin{array}{c}\text { Number of } \\
\text { measurements }\end{array}$ & $\begin{array}{c}\text { Standard } \\
\text { deviation }\end{array}$ \\
\hline $\mathrm{FA}$ & 86.6 & 10 & 1.9 \\
\hline $\mathrm{DR}$ & 87.6 & 17 & 10.8 \\
\hline $\mathrm{IN}$ & 114.4 & 8 & 5.1 \\
\hline $\mathrm{LX}$ & 16.8 & 11 & 1.3 \\
\hline
\end{tabular}

DR

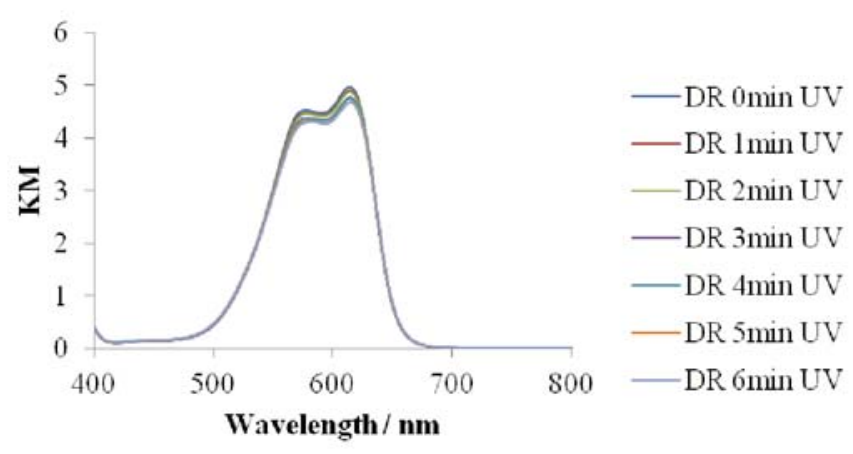

LX

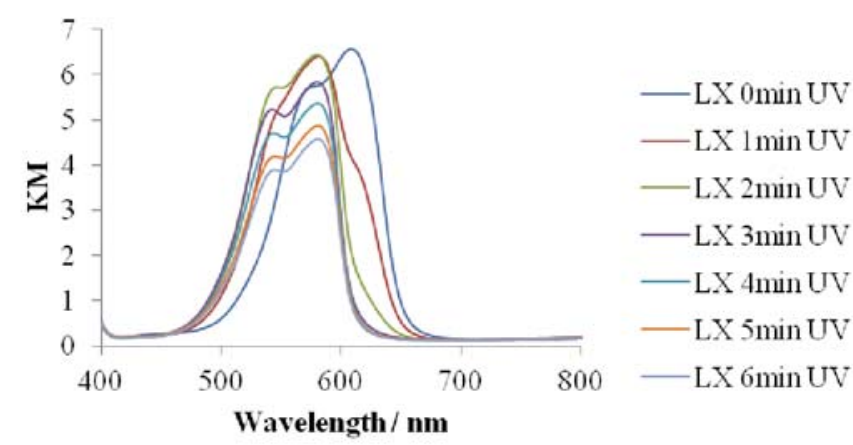

Figure 2. UV-Vis/DR spectra of selected samples from the smart ink test 

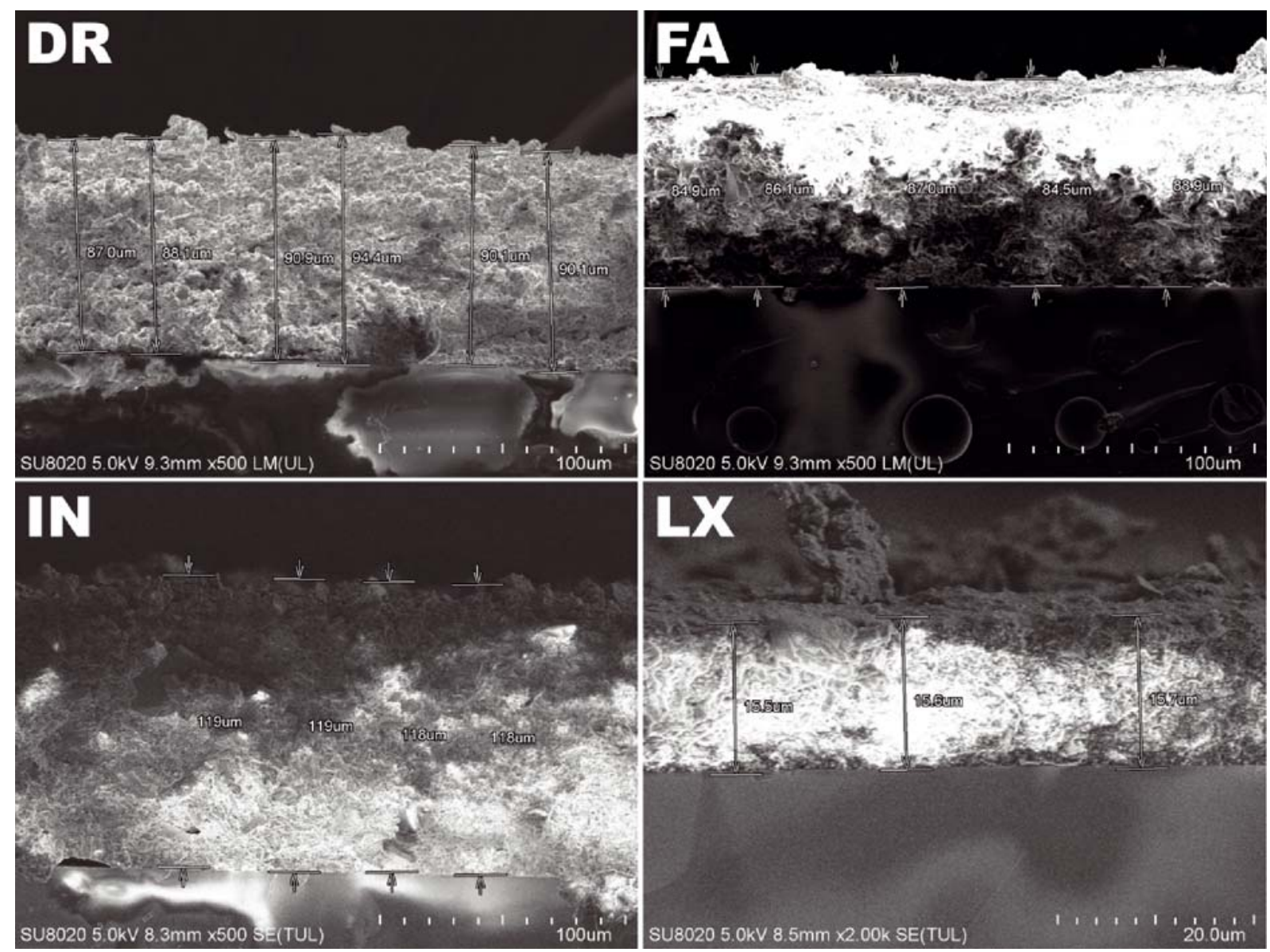

Figure 3. FE-SEM images of paint layers obtained with use of $2 \mathrm{~cm}^{3}$ of various photocatalytic paints

values from measurements of paint layer thickness were listed, with corresponding statistical data.

In next experiments porcelain trays were coated with different volumes of paints and submitted to the photocatalytic decomposition of $\mathrm{BaP}$ under $\mathrm{UV}$ irradiation in the weathering chamber for $60 \mathrm{~min}$. Influence of the photocatalytic paint thickness on the BaP decomposition was illustrated in Figure 4.

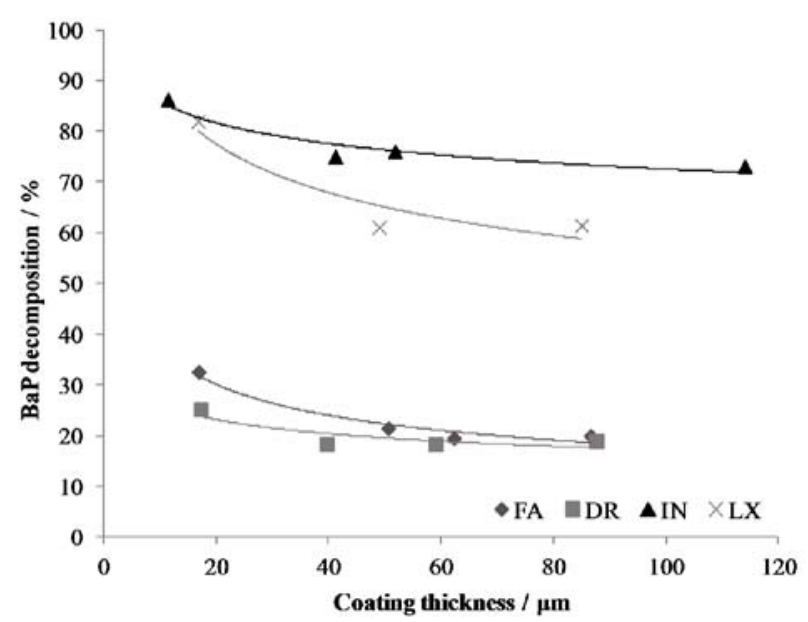

Figure 4. BaP decomposition after 60 min of UV irradiation in relation to the photocatalytic paint coating thickness

Values of BaP extraction from the paint coating were included in the calculations of $\mathrm{BaP}$ decomposition. Percentage of $\mathrm{BaP}$ extraction from the paint surface with acetone solvent, obtained as an average value from 3 independent measurements, equalled to $86,87,81$ and $84 \%$ for FA, DR, IN and LX paints, respectively.

In Figure 4 it can be observed that the percentage of $\mathrm{BaP}$ decomposition after 60 min of $\mathrm{UV}$ irradiation decreases with increase of the paint layer thickness. However, for the increase of layer's thickness above 40 $\mu \mathrm{m}$, amount of decomposed BaP remains stable. Paint layer thickness of around $10-20 \mu \mathrm{m}$ seems to be the limit for occurrence of photocatalytic process. For higher layer thickness, $\mathrm{BaP}$ was partially adsorbed in the porous structure of paint and did not undergo decomposition due to the lack of contact with the UV irradiation. In order to verify this phenomenon, the measurements of depth of UV light absorption through the paint layer were performed.

\section{Measurements of UV absorption by paint coatings}

Measurements of the UV-Vis absorption by the photocatalytic paint coatings were conducted for LX and DR paints (these of the lowest and the highest roughness). Taking into account that all of the used paints are of white colour and both, the composition and surface roughness of DR are quite similar to FA and LX to IN, only two of them were selected for these measurements. UV-Vis emission spectra from the measurements of both incident light and passing through the paint layer of varying thickness were recorded and displayed in Figure 5. From these spectra irradiation of absorbed light in the range of 315-400 $\mathrm{nm}$ was calculated for each paint coating. The percentage of UV absorption by the latex LX and silicate DR paints in relation to the paint layer thickness was presented in Figure 6. 

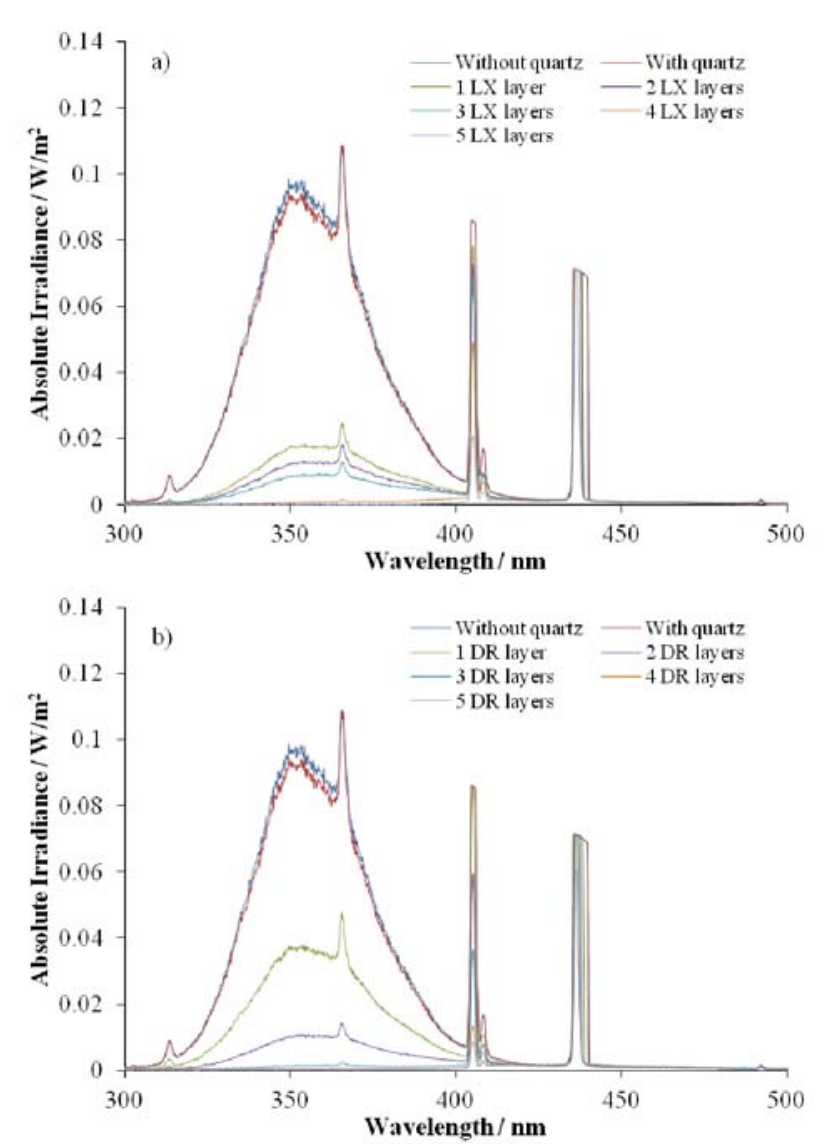

Figure 5. UV light absorption by consecutive layers of photocatalytic paints: a) LX and b) DR

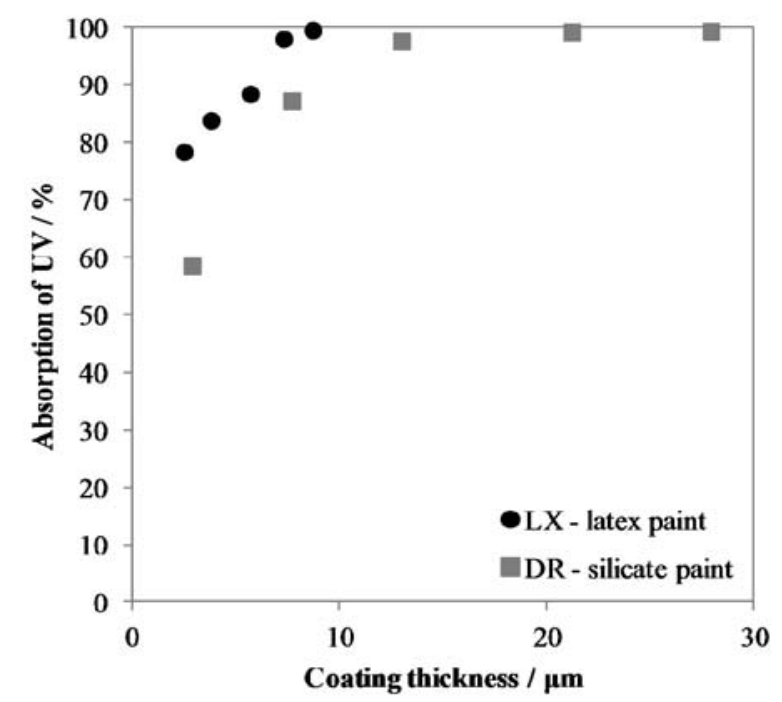

Figure 6. Percentage of UV light absorption by consecutive layers of latex LX and silicate DR photocatalytic paints

It can be observed that over $99 \%$ of UV light in the range of $315-400 \mathrm{~nm}$ was absorbed by the LX paint coating with thickness of around $9 \mu \mathrm{m}$. In the case of DR paint, the same amount of UV light was absorbed by a thicker layer, around $21 \mu \mathrm{m}$. More porous structure of DR paint in comparison to LX caused deeper penetration of UV light. In the case of $\mathrm{TiO}_{2}$ film coatings, some of the researchers noted increase of the photocatalytic activity with increase of the number of coatings up to certain optimal amount ${ }^{27}$. However, reported optimal thickness of the film was different for various structures, it ranged from around $500 \mathrm{~nm}$ to $10 \mu \mathrm{m}^{25-27}$. This was connected with film porosity and roughness. Therefore to compare the photocatalytic activity of paints, the optimal thickness of coating layer should be taken into account, which can be different for various structures of coatings.

\section{CONCLUSIONS}

To summarise the influence of physical and chemical properties of the photocatalytic paints on their effectiveness for decomposition of organic compounds, it can be stated that a thin layer of paint is only active with the thickness equalled the limit of UV penetration through the coating layer. More porous structure of coating results in deeper penetration of UV light. In the case of acrylic paint, the thickness of the photocatalytic layer is around $9 \mu \mathrm{m}$, but for more porous silicate paint, DR, this thickness is extended to $21 \mu \mathrm{m}$.

\section{ACKNOWLEDGEMENTS}

Project was supported by National Science Centre, DEC-011/01/B/ST5/06289.

\section{LITERATURE CITED}

1. Fujishima, A., Zhang, X. \& Tryk, D. (2007). Heterogeneous photocatalysis: From water photolysis to applications in environmental cleanup. Int. J. Hydro. Energ. 322664-322672. DOI: 10.1016/j.ijhydene.2006.09.009.

2. Fujishima, A., Zhang, X. \& Tryk, D. (2008). TiO, photocatalysis and related surface phenomena. Surf. Sci. Rep. 63, 515-582. DOI:10.1016/j.surfrep.2008.10.001.

3. Nakata, K. \& Fujishima, A. (2012). $\mathrm{TiO}_{2}$ photocatalysis: Design and applications. J. Photochem. Photobiol., C. 13, 169-189. DOI: 10.1016/j.jphotochemrev.2012.06.001.

4. Ochiai, T. \& Fujishima, A. (2012). Photoelectrochemical properties of $\mathrm{TiO}_{2}$ photocatalyst and its applications for environmental purification. J. Photochem. Photobiol., C. 13, 247-262. DOI: 10.1016/j.jphotochemrev.2012.07.001.

5. Wang, X., Liu, L. \& Xu, H. (2013). Application of Photocatalytic Concrete Paint and its Effect of Decomposing Vehicle Exhaust. AMR. 683, 98-105. DOI: 10.4028/www.scientific.net/ amr.683.98.

6. Chen, J. \& Poon, C. (2009). Photocatalytic construction and building materials: From fundamentals to applications. Build. Environ. 44, 1899-1906. DOI: 10.1016/j.buildenv.2009.01.002.

7. Auvinen, J. \& Wirtanen, L. (2008). The influence of photocatalytic interior paints on indoor air quality. Atmos. Environ. 42, 4101-4112. DOI: 10.1016/j.atmosenv.2008.01.031. 8. Allen, N., Edge, M., Sandoval, G., Verran, J., Stratton, J. \& Maltby, J. (2005). Photocatalytic Coatings for Environmental Applications. Photochem. Photobiol. 81, 279-290. DOI: 10.1562/2004-07-01-ra-221.1.

9. Salthammer, T. \& Fuhrmann, F. (2007). Photocatalytic Surface Reactions on Indoor Wall Paint. Environ. Sci. Technol. 41, 6573-6578. DOI: 10.1021/es070057m.

10. Maggos, T., Bartzis, J., Liakou, M. \& Gobin, C. (2007). Photocatalytic degradation of $\mathrm{NO}_{x}$ gases using $\mathrm{TiO}_{2}$-containing paint: A real scale study. J. Hazard. Mater. 146, 668-673. DOI: 10.1016/j.jhazmat.2007.04.079.

11. Paušová, Š., Krýsa, J., Jirkovský, J., Prevot, V. \& Mailhot, G. (2014). Preparation of $\mathrm{TiO}_{2}-\mathrm{SiO}_{2}$ composite photocatalysts for environmental applications. J. Chem. Technol. Biotechnol. 89, 1129-1135. DOI: $10.1002 /$ jctb.4436.

12. Águia, C., Ângelo, J., Madeira, L. \& Mendes, A. (2010). Influence of photocatalytic paint components on the photoactivity of P25 towards NO abatement. Catal. Today. 151, 77-83. DOI: 10.1016/j.cattod.2010.01.057. 
13. Marolt, T., Škapin, A., Bernard, J., Živec, P. \& Gaberšček, M. (2011). Photocatalytic activity of anatase-containing facade coatings. Surf. Coat. Technol. 206, 1355-1361. DOI: 10.1016/j. surfcoat.2011.08.053.

14. Baudys, M., Krýsa, J., Zlámal, M. \& Mills, A. (2015). Weathering tests of photocatalytic facade paints containing $\mathrm{ZnO}$ and ${ }_{\mathrm{TiO} 2}$. Chem. Eng. J. 261, 83-87. DOI: 10.1016/j. cej.2014.03.112.

15. Monteiro, R., Lopes, F., Silva, A., Ângelo, J., Silva, G., Mendes, A., Boaventura, R.A.R. \& Vilar, V.J.P. (2014). Are $\mathrm{TiO}_{2}$-based exterior paints useful catalysts for gas-phase photooxidation processes? A case study on n-decane abatement for air detoxification. Appl. Catal., B. 147, 988-999. DOI: 10.1016/j.apcatb.2013.09.031.

16. Tryba, B., Homa, P., Wróbel, R. \& Morawski, A. (2014). Photocatalytic decomposition of benzo-[a]-pyrene on the surface of acrylic, latex and mineral paints. Influence of paint composition. J. Photochem. Photobiol., A. 286, 10-15. DOI: 10.1016/j.jphotochem.2014.04.012.

17. Zuccheri, T., Colonna, M., Stefanini, I., Santini, C. \& Gioia, D. (2013). Bactericidal Activity of Aqueous Acrylic Paint Dispersion for Wooden Substrates Based on $\mathrm{TiO}_{2}$ Nanoparticles Activated by Fluorescent Light. Mater. 6, 3270-3283. DOI: 10.3390/ma6083270.

18. Pal, S., Contaldi, V., Licciulli, A. \& Marzo, F. (2016). Self-Cleaning Mineral Paint for Application in Architectural Herit. Coat. 6, 48-57. DOI: 10.3390/coatings6040048.

19. Akpan, U. \& Hameed, B. (2009). Parameters affecting the photocatalytic degradation of dyes using $\mathrm{TiO}_{2}$-based photocatalysts: A review. J. Hazard. Mater. 170, 520-529. DOI: 10.1016/j.jhazmat.2009.05.039.

20. Barrocas, B., Monteiro, O., Jorge, M. \& Sério, S. (2013). Photocatalytic activity and reusability study of nanocrystalline $\mathrm{TiO}_{2}$ films prepared by sputtering technique. Appl. Surf. Sci. 264, 111-116. DOI: 10.1016/j.apsusc.2012.09.136.

21. Addamo, M., Augugliaro, V., Di Paola, A., García-López, E., Loddo, V., Marcì, G. \& Palmisano, L. (2008). Photocatalytic thin films of $\mathrm{TiO}_{2}$ formed by a sol-gel process using titanium tetraisopropoxide as the precursor. Thin Sol. Films. 516, 3802-3807. DOI: 10.1016/j.tsf.2007.06.139.

22. Ismail, A., Bahnemann, D., Rathousky, J., Yarovyi, V. \& Wark, M. (2011). Multilayered ordered mesoporous platinum/ titania composite films: does the photocatalytic activity benefit from the film thickness? J. Mater. Chem. 21, 7802-7810. DOI: $10.1039 / \mathrm{c} 1 \mathrm{jm} 10366 \mathrm{k}$.

23. Hao, D., Yang, Z., Jiang, C. \& Zhang, J. (2014). Synergistic photocatalytic effect of $\mathrm{TiO}_{2}$ coatings and p-type semiconductive $\mathrm{SiC}$ foam supports for degradation of organic contaminant. Appl. Catal. B. 144, 196-202. DOI: 10.1016/j. apcatb.2013.07.016.

24. Malagutti, A., Mourão, H., Garbin, J. \& Ribeiro, C. (2009). Deposition of $\mathrm{TiO}_{2}$ and $\mathrm{Ag}: \mathrm{TiO}_{2}$ thin films by the polymeric precursor method and their application in the photodegradation of textile dyes. Appl. Catal. B. 90, 205-212. DOI: 10.1016/j. apcatb.2009.03.014.

25. Kumar, K., Raju, N. \& Subrahmanyam, A. (2011). Thickness dependent physical and photocatalytic properties of ITO thin films prepared by reactive DC magnetron sputtering. Appl. Surf. Sci. 257, 3075-3080. DOI: 10.1016/j.apsusc.2010.10.119.

26. Chen, Y. \& Dionysiou, D. (2006). Correlation of structural properties and film thickness to photocatalytic activity of thick $\mathrm{TiO}_{2}$ films coated on stainless steel. Appl. Catal. B. 69, 24-33. DOI: 10.1016/j.apcatb.2006.05.002.

27. Wu, C., Lee, Y., Lo, Y., Lin, C. \& Wu, C. (2013). Thickness-dependent photocatalytic performance of nanocrystalline $\mathrm{TiO}_{2}$ thin films prepared by sol-gel spin coating. Appl. Surf. Sci. 280, 737-744. DOI: 10.1016/j.apsusc.2013.05.053.

28. Mills, A., Hepburn, J., Hazafy, D., O'Rourke, C., Wells, N., Krýsa, J., Baudys, M., Zlamal, M., Bartkova, H., Hill, C.E., Winn, K.R., Simonsen, M.E., Søgaard, E.G., Banerjee, S., Fagan,
R. \& Pillai, S.C. (2014). Photocatalytic activity indicator inks for probing a wide range of surfaces. J. Photochem. Photobiol., A. 290 63-71. DOI: 10.1016/j.jphotochem.2014.06.007.

29. Mills, A., O’Rourke, C., Lawrie, K. \& Elouali, S. (2014). Assessment of the Activity of Photocatalytic Paint Using a Simple Smart Ink Designed for High Activity Surfaces. ACS Appl. Mater. Inter. 6, 545-552. DOI: 10.1021/am4046074.

30. Mills, A., Hepburn, J., Hazafy, D., O’Rourke, C., Krýsa, J., Baudys, M., Zlamal, M., Bartkova, H., Hill, C.E., Winn, K.R., Simonsen, M.E., Søgaard, E.G., Pillai, S.C., Leyland, N.S., Fagan, R., Neumann, F., Lampe, C. \& Graumann, T. (2013). A simple, inexpensive method for the rapid testing of the photocatalytic activity of self-cleaning surfaces, J. Photoch. Photobio. A. 272, 18-20. DOI: 10.1016/j.jphotochem.2013.08.004.

31. Tryba, B., Wróbel, R., Homa, P. \& Morawski, A. (2015). Improvement of photocatalytic activity of silicate paints by removal of $\mathrm{K}_{2} \mathrm{SO}_{4}$. Atmos. Environ. 115, 47-52. DOI: 10.1016/j. atmosenv.2015.05.047. 